\title{
QUALITY MANAGEMENT SYSTEMS IN SMALL AND MEDIUM MECHANICAL ENGINEERING ENTERPRISES IN LATVIA
}

\author{
G. Civcisa ${ }^{1, *}$, J. Rudnevs ${ }^{1}$ and A. Grislis ${ }^{2}$ \\ ${ }^{1}$ Institute of Mechanical Engineering, Faculty of Transport and Mechanical \\ Engineering, Riga Technical University \\ Ezermalas 6k, LV-1006, Riga, Latvia \\ Email: guna.civcisa@rtu.lv \\ ${ }^{2}$ Institute of Road Transport, Faculty of Transport and Mechanical Engineering, \\ Riga Technical University \\ Ezermalas 6k, LV-1006, Riga, Latvia
}

\begin{abstract}
ISO 9001 quality management systems is one of globally well-known standards developed by the International Organization for Standardization (ISO). It is widely implemented in different organisations, regardless of their size class and sector of activity. The aim of this study is to collect and analyse information on mechanical engineering enterprises by size classes in Latvia that have been certified in conformity with ISO 9001 requirements. This study presents findings from the research focused on mechanical engineering. Therefore, an overview of the most popular management system standard in the mechanical engineering sector has been done. A comparative analysis has been applied in order to determine the proportion of enterprises with quality management systems certified in accordance with the ISO 9001 standard by industrial sector in Latvia and worldwide. The expected research outcome is a distribution of mechanical engineering enterprises by size classes (micro-, small-, medium-sized and large-scale enterprises) in Latvia certified with ISO 9001.
\end{abstract}

Keywords: Quality management systems; mechanical engineering; micro-, small- and medium-sized enterprises.

\section{INTRODUCTION}

Asin the whole of Europe, the largest part of the national economy in Latviais constituted by the proportion of small- and medium-sized enterprises (SMEs). SMEs accounted for $99.5 \%$ of the total number of enterprises $(80,000)$ in 2011 . Classification of SMEs by size classes shows that $84.7 \%$ were micro-, $12.3 \%$ small-, and $2.5 \%$ medium-sized enterprises. Therefore, it is crucially important to focus on issues regarding SMEs. The mechanical engineering sector is among the traditional manufacturing industries in Latvia, which is explicitly aimed at export. After the stabilisation of the country's economic situation (at the end of 2009 to the beginning of 2010)this industry showed medium rapid growth and has made significant contributions to the processing industry and the national economy in general [1]. ISO 9001 is the most widely-implemented standard among other ISO management systems regardless of industrial sector. The ISO 9001 standard is recognised and applied throughout the world and it has been implemented in more than one million enterprises. According to the 
annual surveys of the ISO [2], the total number of issued certificates tends to increase year by year. The situation in Latvia is similar - the total number of certified organisations grows every year, but by a much smaller number due to the small size of the economy. Practically, it is impossible to identify the total number of QMS users and the spread of the standard country-by-country. The only way to identify existing users of the standard and to count the number of standard implementers is when a user (an organisation of any type) of the ISO 9001 standard decides to certify its QMS according to the requirements of the standard. A common method of identifying users is gathering information on the number of certificates of conformity to requirements of the ISO 9001 that have been issued by certification bodies.

A number of recent publications show that the ISO 9000 standard has a positive impact on internal and external operational aspects of certified organisations [3], a positive effect on financial performance [4], on improvements in both project and financial management practices in construction environments [5], that it provides faster cash and material flows [6] and that it helps the growth of organisations [7] in the supply chain field. Another study from the perspective of manufacturing SMEs found that there is an improvement in product delivery performance, product quality, product volume flexibility and product variety flexibility after certification [8]. Among the SMEs that have obtained certification with more than one management standard, the main benefits have been improvements in their internal organisation and external image [9]. No scientific papers have been found in an analysis of previous research on how actively SMEs of mechanical engineering in Latvia implement a certified QMS according to the requirements of ISO 9001. A technique was developed for statistical data collection and analysis to achieve the aim of this study and identify the proportion of certified enterprises in mechanical engineering by size classes. The research object is mechanical engineering enterprises that already have a certified QMS with the 2008 version of ISO 9001. Quantitative analysis methods have been used to characterise the data set used for this study.

\section{METHODOLOGY}

A technique for gathering and analysing statistical data in order to identify the proportion of SMEs in mechanical engineering which have implemented a certified QMS has been developed. A technique for the establishment of the proportion of certified QMS envisages two steps:

i) Collect adequate data on each study object;

ii) Systematise the collected data and carry out statistical analysis.

The first step of the developed technique includes two important features for the selection of enterprises. The first feature is the existence of the ISO 9001 certificate; the second is the size of the company according to the number of employees. Data for research purposes were retrieved from the databases of the Latvian Association for Quality [10] and the Association of Mechanical Engineering and Metalworking Industries of Latvia (MASOC, 2011), where a list of certified companies is available. Which group of size class each enterprise belonged to was determined according to the Recommendation of European Commission 2003/361/EC. In accordance with this Recommendation of what constitutes an SME, the micro category consists of enterprises with less than 10 employees, the small category consists of enterprises with between 10 
and 49 employees, and the category of medium-sized enterprises consists of enterprises with between 50 and 249 employees [11]. After the collection of an appropriate data set, the second step of the technique was carried out and the obtained data were systematised and statistical analysis was conducted. During the analysis, each enterprise was observed and an electronic database was created using Microsoft Excel. All the necessary information on each observed enterprise was inserted in this database to systematise the selected data according to the following categories: title of enterprise; number of employees; code of industrial sector; certificates, etc. The systematisation of the data has allowed for the convenient analysis and interpretation of the observed results. The number of ISO 9001 certificates issued to the industrial sector was determined according to European Accreditation Code (EA Code) classification [12], which is used by the ISO, as well as accreditation and certification institutions. Mechanical engineering enterprises were classified according to EA Codes, and according to this the research data analysis and result summarisation was done. It is stated in this research that the mechanical engineering sector covers two EA Codes, as follows:

- $\quad$ basic metals and fabricated metal products (EA 17);

- machinery and equipment (EA 18).

When the database was created to gather the information about mechanical engineering enterprises certified to the requirements of the ISO 9001 standard, the data were processed and analysed in four groups broken down by company size classes.

\section{RESULTS AND DISCUSSION}

\section{Data Analysis}

According to the latest data of the Central Statistical Bureau of Latvia [13] and calculations made by the authors (Figure 1), at the end of 2010 there were 1,841 enterprises, while at the end of 2011 there were 1,814 enterprises in the mechanical engineering sector in Latvia. In 2011, about1 804 enterprises, or over 99\% of all enterprises, were SMEs employing fewer than 250 employees. About 1,348, or 74\%, of mechanical engineering enterprises in Latvia were micro, employing 0-9 people.

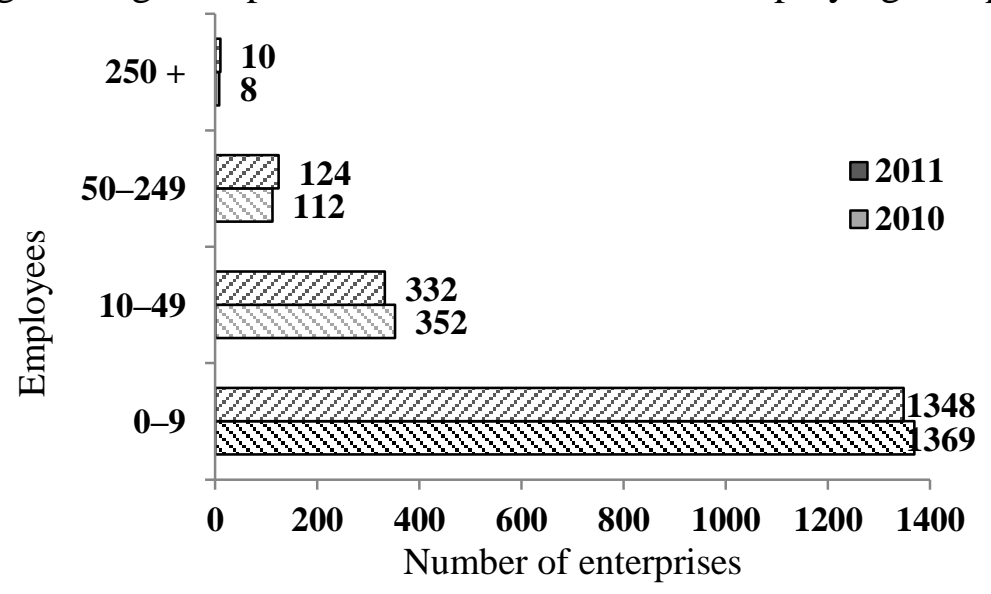

Figure 1. Mechanical engineering enterprises by size class in Latvia, 2009 and 2010. Source: author's calculation using CSB data [13]. 
According to the latest publicly-available data on the national level, in January 2010there were 703 issued ISO 9001 certificates in Latvia [10]. The newest available ISO survey shows that in 2011 there were 787, while in 2012 there were 791 issued ISO 9001 certificates in Latvia [2].In this study, a further analysis has been carried out based on a data set obtained using two databases, provided by LAQ and MASOC, respectively. The LAQ database was chosen because it gives the overall situation of certification in Latvia, but the MASOC database provides extended information on mechanical engineering enterprises. Based on data selection and processing, it was found that in 2011 there were 48 mechanical engineering enterprises certified by ISO 9001 in MASOC (MASOC, 2012). According to the database of LAQ, it was stated that overall in 2010there were 46 mechanical engineering enterprises in Latvia which had the ISO 9001 certificate of compliance [10]. Thus, it can be stated that the whole population size was estimated within the research. All these numbers of enterprises have been calculated within the limits of the sector under research. Since the results of the analyses cannot be completely transferred to the population, a 95\% confidence level is assumed. A slight shifting in the number of enterprises can be explained by the fact that statistical data cannot be obtained in a one-year perspective.

\section{The ISO 9001 Certificates by Industrial Sector}

The ISO 9001 is also the most widely used standard in the mechanical engineering sector. This section of the article describes the results of an analysis that was carried out to estimate the spread of certified QMS in mechanical engineering enterprises. In the context of this analysis, a comparison with other industry sectors in the world in general and in Latvia in particular was done. As was previously defined in the methodology of this study, the mechanical engineering sector covers EA Codes 17 and 18. The growth of certified enterprises has increased from 154,060 mechanical engineering enterprises in 2010 to 180,532 in 2012 [2]. According to statistical data, in 2010 the extent of ISO 9001 certificates on a global scale, broken down by industrial sectors, shows that among the top five sectors two are mechanical engineering sectors.

Table 1. The number of ISO 9001 certificates in the world by industrial sector.

\begin{tabular}{llc}
\hline No & Description of industrial sector according to EA Codes & $\begin{array}{c}\text { Relative } \\
\text { frequency, \% }\end{array}$ \\
\hline 1 & EA 17 Basic metals and metal products manufacturing & 13 \\
2 & EA 28 Construction & 11 \\
3 & EA 19 Electrical and optical equipment & 11 \\
4 & EA 18 Machinery and equipment & 8 \\
5 & EA 29 Wholesale and retail trade, automotive, motorcycles, & 7 \\
& personal and household goods & 5 \\
6 & EA 14 Rubber and plastic products & 5 \\
7 & EA 35 Other Services & 40 \\
8 & Other sectors & \\
\hline
\end{tabular}

Source: author's calculation using ISO survey[2]

As one can see in Table 1, the total number of mechanical engineering enterprises in the world was estimated at $21 \%$ of all enterprises certified by ISO 9001[2]. According to the results of ISO data analysis, one can conclude that certification of 
QMS in mechanical engineering enterprises, which evaluates conformity with ISO 9001 requirements, is widespread and should be characterised as high.

This section of the article also includes information on the extent of ISO 9001 certificates in the industrial sector in Latvia, as well as which industrial sector most often chooses to certify compliance of QMS to ISO 9001 standard requirements. Table 2 includes the sectors where the number of enterprises which have evaluated compliance to the ISO 9001 requirements reaches at least $5 \%$ of the total number of enterprises. It was stated that $5 \%$ of the metal and metal product manufacturing sector (EA 17) enterprises have certified QMS to ISO 9001 requirements by analysing the situation of mechanical engineering in Latvia. The devices and equipment manufacturing sector (EA18) is not included in Table 2, as the number of certified enterprises only constitutes $1 \%$ of the total number of certified enterprises in Latvia. Based on the results shown in Table 1 and 2, it could be determined that about $6 \%$ (a total number of46) of 703 enterprises which had a certified QMS according to the requirements of ISO 9001 in 2010 are mechanical engineering enterprises in Latvia. In comparison, $21 \%$ of all enterprises in the world which have certified QMS according to the requirements of ISO 9001 are mechanical engineering enterprises. Comparatively, the share of certified mechanical engineering enterprises is about 3.5 times smaller in Latvia than it is on average globally. Thus, it shows that the certification of compliance with ISO 9001 requirements in mechanical engineering enterprises in Latvia should be characterised as low. This analysis was done to identify the range of enterprises by industrial sector that are certified with ISO 9001 to determine the proportion of certified enterprises by size class in mechanical engineering in Latvia.

Table 2. The number of ISO 9001 certificates in Latvia by industrial sector.

\begin{tabular}{llc}
\hline No & Description of industrial sector according to EA Codes & $\begin{array}{c}\text { Relative } \\
\text { frequency, \% }\end{array}$ \\
\hline 1 & EA 28 Construction & 18 \\
2 & EA 35 Other services & 12 \\
3 & EA 29 Wholesale and retail trade; Repair of motor vehicles, & 10 \\
& motorcycles and personal and household goods & 9 \\
4 & EA 31 Transport, storage and communication & 8 \\
5 & EA 34 Engineering services & 5 \\
6 & EA 17 Basic metals and fabricated metal products & 5 \\
7 & EA 19 Electrical and optical equipment & 5 \\
8 & EA 36 Public administration & 28 \\
9 & Other sectors
\end{tabular}

Source: author's calculation using LAQ data [10]

\section{ISO 9001 Certified Enterprises}

The findings of this section demonstrate the distribution of ISO 9001:2008 certified enterprises in mechanical engineering by size class in Latvia. The distribution of the number of enterprises by size classis presented in Figure 2. The results gained by the analysis show that the vast majority of certified mechanical engineering enterprises included in the research sample are SMEs (92\%) -the largest part of them (59\%)is constituted by medium enterprises, while nearly one third (29\%) of enterprises are small ones. The smallest part (4\%) of SMEs is constituted by micro enterprises. A relatively 
small part $(8 \%)$ of all enterprises is large companies in Latvia. Finally, it is interesting to note that, by doing a comparison between the distribution of size classes of all enterprises in Latvia [14] and the situation in the mechanical engineering field particularly, one can conclude that certified QMS according to ISO 9001 are more widely used (by 6 percentage points) in SMEs from the mechanical engineering sector than in all enterprises in Latvia. The share of all small- and medium-sized enterprises certified in Latvia is nearly similar (respectively, $42 \%$ and 39\%), but the share of certified medium mechanical engineering enterprises is twice as large as the group of small enterprises (respectively, 59\% and 29\%). Although certification of QMS according to the ISO 9001 standard is only one of the quality management approaches, data on the number of certified enterprises is one of the most widely-used evaluation indicators.

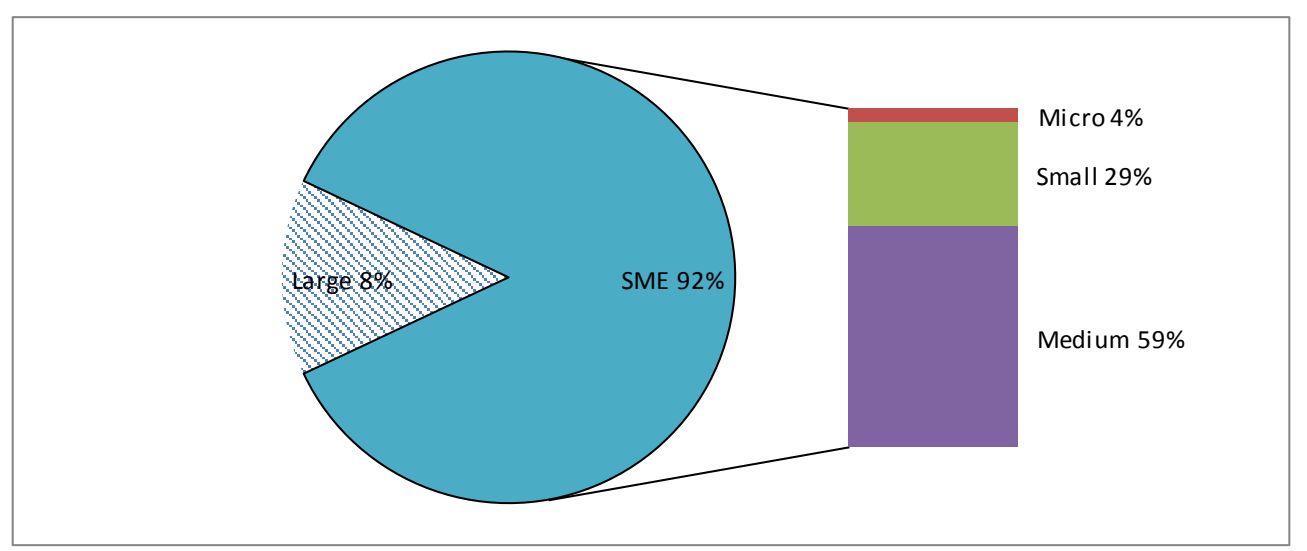

Figure 2. A distribution of the ISO 9001certificates by enterprise size class in the mechanical engineering sector.

\section{CONCLUSIONS}

This study provides information and results of research about how actively mechanical engineering SMEs in Latvia apply to certify QMS according to ISO 9001. The conducted research is the first such systematised data collection, which cannot be retrieved from annual ISO surveys and publicly-available databases of other organisations (for example, certification bodies). The results of the analysis on the distribution of certified enterprises allows for the characterisation of enterprises by size class in Latvia and allows for conclusions to be about them on this basis. The obtained results are useful for comparing the growth or reduction tendencies by year on national, regional and international scales. Considering the importance and input of SMEs into the Latvian economy, the authors suggest that representatives of SMEs should be more widely involved and informed about QMS standards and other Quality Systems, as well as about the possibilities to apply them. Further research could be conducted to determine the proportion of ISO 9001-certified enterprises within any other industry sector. 


\section{ACKNOWLEDGEMENTS}

The authors would like to thank to Association of Mechanical Engineering and Metalworking Industries of Latvia for permission to use data.

\section{REFERENCES}

[1] Latvia MoEotRo. Economic Development of Latvia. 2011. p. 144.

[2] ISO. ISO Survey. Switzerland: International Organization for Standardization; 2012.

[3] Boiral O. ISO 9000 and organizational effectiveness: A systematic review. 2012.

[4] Sharma DS. The association between ISO 9000 certification and financial performance. The International Journal of Accounting. 2005;40:151-72.

[5] Din S, Abd-Hamid Z, Bryde DJ. ISO 9000 certification and construction project performance: The Malaysian experience. International Journal of Project Management. 2011;29:1044-56.

[6] Lo CK, Yeung AC, Cheng T. ISO 9000 and supply chain efficiency: empirical evidence on inventory and account receivable days. International Journal of Production Economics. 2009;118:367-74.

[7] Terlaak A, King AA. The effect of certification with the ISO 9000 Quality Management Standard: A signaling approach. Journal of Economic Behavior \& Organization. 2006;60:579-602.

[8] Koc T. The impact of ISO 9000 quality management systems on manufacturing. Journal of Materials Processing Technology. 2007;186:207-13.

[9] Santos G, Mendes F, Barbosa J. Certification and integration of management systems: the experience of Portuguese small and medium enterprises. Journal of cleaner production. 2011;19:1965-74.

[10] LAQ. Management Systems and Certification. Latvia2010.

[11] Commission E. Commission Recommendation 2003/361/EC of 6 May 2003 concerning the definition of micro, small and medium-sized enterprises. Official Journal of the European Union. Luxembourg: European Commission; 2003. p. 36.

[12] IAF TC. IAF Informative Document In: () International Accreditation Forum I, editor. IAF ID 1:2010 Canada2010.

[13] CSB. Database: Industry. Key entrepreneurship indicators in industry by number of employees. In: Latvia CSBo, editor. Latvia2013.

[14] Čivčiša G. Share of small and medium-sized enterprises with certified ISO 9001 quality management systems in Latvia. publication editionName. 2010;1:56-67. 